\title{
KAJIAN YURIDIS PENGADAAN TANAH UNTUK PEMBANGUNAN JALAN TOL BATANG-SEMARANG II SEKSI V DI KOTA SEMARANG \\ Oleh : \\ Latif
}

PNS di Kantor Pertanahan Kota Semarang

\begin{abstract}
ABSTRAK
Mekanisme perubahan status harta benda wakaf yang terkena pengadaan tanah untuk pembangunan jalan tol Batang-Semarang II seksi V di Kota Semarang saat ini dalam pelaksanaannya tidak berjalan sesuai ketentuan perundang - undangan karena terdapat benturan antara Undang-undang Nomor 41 Tahun 2004 dan Peraturan Pemerintah Nomor 42 Tahun 2006 yang mengatur Wakaf dengan Undang-undang Nomor 2 Tahun 2012 dan Peraturan Presiden Nomor 71 Tahun 2012 tentang pengadaan tanah serta Peraturan Presiden Nomor 58 tahun 2017 yang mengatur Percepatan Pembangunan Infrastruktur.

Penelitian ini menggunakan metode pendekatan yuridis normatif, spesifikasi penelitian menggunakan metode deskriptif analitis, sumber data menggunakan data sekunder dari hukum positif, bahan hukum primer, sekunder dan tersier.

Pelaksanaan perubahan status harta benda wakaf yang terkena pengadaan tanah untuk pembangunan jalan tol Batang-Semarang II Seksi V di Kota Semarang tidak sesuai dengan ketentuan perundang-undangan yang mengatur tentang mekanisme perubahan status harta benda wakaf. Hal-hal yang menghambat proses perubahan status harta benda wakaf adalah :1. Faktor Internal (Nazhir, KUA, Kementerian Agama (Pusat, Provinsi, Kota Semarang), BWI, dan Pemerintah Kota Semarang, PPK Jalan Tol, Badan Pertanahan Nasional dan Tim Pelaksana Pengadaan tanah ), 2. Faktor Eksternal : Kesulitan mencari tanah pengganti.Terdapat Penolakan dari Warga Sekitar tanah pengganti. Adanya Spekulan Tanah / Kelompok Kepentingan.
\end{abstract}

Kata Kunci: Perubahan Status Harta Benda Wakaf, Pengadaan Tanah

\begin{abstract}
The mechanism of change in the status of endowments of land endowments for the construction of Batang-Semarang II toll road section V in Semarang City is currently not in accordance with the provisions of legislation because there is a clash between Law Number 41 Year 2004 and Government Regulation Number 42 Year 2006 governing Wakaf with Law No. 2 of 2012 and Presidential Regulation No. 71 of 2012 on land acquisition and Presidential Regulation No. 58 of 2017 which regulate the Acceleration of Infrastructure Development.

This research uses normative juridical approach method, research specification using analytical descriptive method, data source use secondary data from positive law, primary law material, secondary and tertiary.
\end{abstract}


Implementation of changes in the status of endowments of land endowments for the construction of Batang-Semarang II toll road section Section V in Semarang City is not in accordance with the provisions of legislation regulating the mechanism of change of wakaf property status. The things that hamper the process of changing the status of wakaf property are: 1. Internal Factors (Nazhir, KUA, Ministry of Religious Affairs (Central, Provincial, Semarang City), BWI and Semarang City Government, Toll Road PPK, National Land Agency and Land Acquisition Team) 2. External Factors: Difficulty in finding replacement land. Refusal of the Residents Around the replacement land. The existence of Land Speculators / Interest Groups.

\section{Keywords: Change of Wakaf Property Status, Land Procurement}

\section{A. Latar Belakang}

Tanah merupakan salah satu sumber daya alam yang penting untuk kelangsungan hidup umat manusia. Hubungan manusia dengan tanah bukan hanya sekedar sebagai tempat hidup, tetapi lebih dari itu tanah memberikan sumber daya bagi kelangsungan hidup umat manusia. Bagi bangsa Indonesia tanah adalah karunia Tuhan Yang Maha Esa dan merupakan kekayaan nasional, serta hubungan antara bangsa Indonesia dengan tanah bersifat abadi. oleh karena itu harus dikelola secara cermat dan penuh tanggungjawab untuk masa sekarang maupun untuk masa yang akan datang. ${ }^{1}$

Persoalan tanah dalam pembangunan untuk kepentingan umum sebagaimana diatur dalam Undang-

1 Boedi Harsono, 1999, Hukum Agraria Indonesia ( Sejarah Pembentukan Undang-Undang Pokok Agraria), Djambatan, Jakarta, hlm. 23 undang No. 2 Tahun 2012 tidak terlepas dari permasalahan perwakafan. Pada hakekatnya harta benda wakaf (tanah wakaf) sebagaimana diatur dalam pasal 40 Undang-undang No. 41 Tahun 2004 tentang wakaf dan Peraturan Pemerintah Nomor 42 Tahun 2006 tentang Pelaksanakan Undang-Undang Nomor 41 Tahun 2004 tentang Wakaf, bahwa Harta benda wakaf yang sudah diwakafkan dilarang untuk : a.dijadikan jaminan, b. disita, c.dihibahkan, d. dijual, e.diwariskan, f.ditukar, atau g.dialihkan dalam bentuk pengalihan hak lainnya.

Wakaf bagi masyarakat Islam dapat bermakna sebagai ibadah, apabila wakaf berupa tanah atau bangunan itu digunakan untuk kepentingan umum seperti tanah yang di "wakafkan" untuk bangunan tempat ibadah, untuk keperluan pembiayaan fakir miskin, dan 
lain-lain sebagainya. Tanah wakaf pada dasarnya adalah "tanah untuk Tuhan". 2

Terdapat pengecualian, apabila harta benda wakaf yang telah diwakafkan digunakan untuk kepentingan umum sesuai dengan rencana umum tata ruang (RUTR) berdasarkan ketentuan peraturan perundang-undangan yang berlaku dan tidak bertentangan dengan syariah dan hanya dapat dilakukan setelah memperoleh izin tertulis dari Menteri atas persetujuan Badan Wakaf Indonesia. Harta benda wakaf yang sudah diubah statusnya karena adanya pengecualian wajib ditukar dengan harta benda yang mempunyai manfaat dan nilai tukar sekurang-kurangnya sama dengan harta benda wakaf semula.

Kegiatan Pengadaan tanah untuk pembangunan Jalan Tol BatangSemarang II Seksi V di Kota Semarang termasuk kategori proyek strategis yang mendapatkan prioritas dari pemerintah sehingga termasuk dalam program percepatan Pelaksanaan Proyek Startegis Nasiorial (PSN) sebagaimana diatur dengan Peraturan Presiden Nomor 3 Tahun 2016 dan diperbaharui

2 Brahmana Adhie dan Hasan Basri Nata Menggala, 1998, Reformasi Tanah, Mandar, Jakarta, hlm. 37 dengan Peraturan Presiden Nomor 58

Tahun 2017 tentang perubahan Peraturan Presiden Nomor 3 Tahun 2016 tentang Percepatan Pelaksanaan Proyek Startegis Nasional sehingga dilakukan upaya-upaya percepatan pelaksanaan pengadaan tanahnya, termasuk didalamnya ketika bersinggungan dengan harta benda wakaf, baik berupa tempat ibadah, tempat pendidikan/sekolah, makam dan seterusnya dan belum terselesaikan sebagaimana diatur dalam perundangundangan, maka hal ini menarik untuk diteliti.

\section{B. Perumusan Masalah}

1. Bagaimanakah mekanisme perubahan status harta benda wakaf yang terkena pengadaan tanah untuk pembangunan jalan tol Batang-Semarang II seksi V di Kota Semarang ?

2. Hal-hal apa saja yang menghambat proses perubahan status harta benda wakaf yang terkena pengadaan tanah untuk pembangunan jalan tol BatangSemarang II Seksi V di Kota Semarang? 


\section{Pembahasan}

1. Mekanisme perubahan status harta benda wakaf yang terkena pengadaan tanah untuk pembangunan jalan tol Batang-Semarang II seksi V di Kota Semarang

Sesuai ketentuan peraturan perundang-undangan bahwa mekanisme perubahan Status / penukaran harta benda wakaf yang akan diubah statusnya menurut Pasal 51 Peraturan Pemerintah Nomor 42 Tahun 2006 Tentang Pelaksanaan Undang-Undang Nomor 41 Tahun 2004 Tentang Wakaf, yaitu dilakukan sebagai berikut:

(a) Nazhir mengajukan permohonan tukar ganti kepada Menteri melalui Kantor Urusan Agama Kecamatan setempat dengan menjelaskan alasan perubahan status/tukar menukar tersebut;

(b) Kepala KUA Kecamatan meneruskan permohonan tersebut kepada Kantor Departemen Agama kabupaten/kota; (c) Kepala kantor Departemen Agama Kabupaten / Kota setelah menerima permohonan tersebut membentuk tim dengan susunan dan maksud seperti dalam Pasal 49 ayat (4), dan selanjutnya Bupati / Walikota setempat membuat Surat Keputusan;

(d) Kepala Kantor Departemen Agama Kabupaten / Kota meneruskan permohonan tersebut dengan dilampiri hasil penilaian dari tim kepada Kepala Kantor Wilayah Departemen Agama Provinsi dan selanjutnya meneruskan permohonan tersebut kepada Menteri Agama, dan e) Setelah mendapatkan persetujuan tertulis dari Menteri Agama, maka tukar ganti dapat dilaksanakan dan hasilnya harus dilaporkan oleh Nazhir ke Kantor Pertanahan dan / atau lembaga terkait untuk pendaftaran lebih lanjut. 
MEKANISME PENUKARAN HARTA BENDA WAKAF (PP 42/2006)

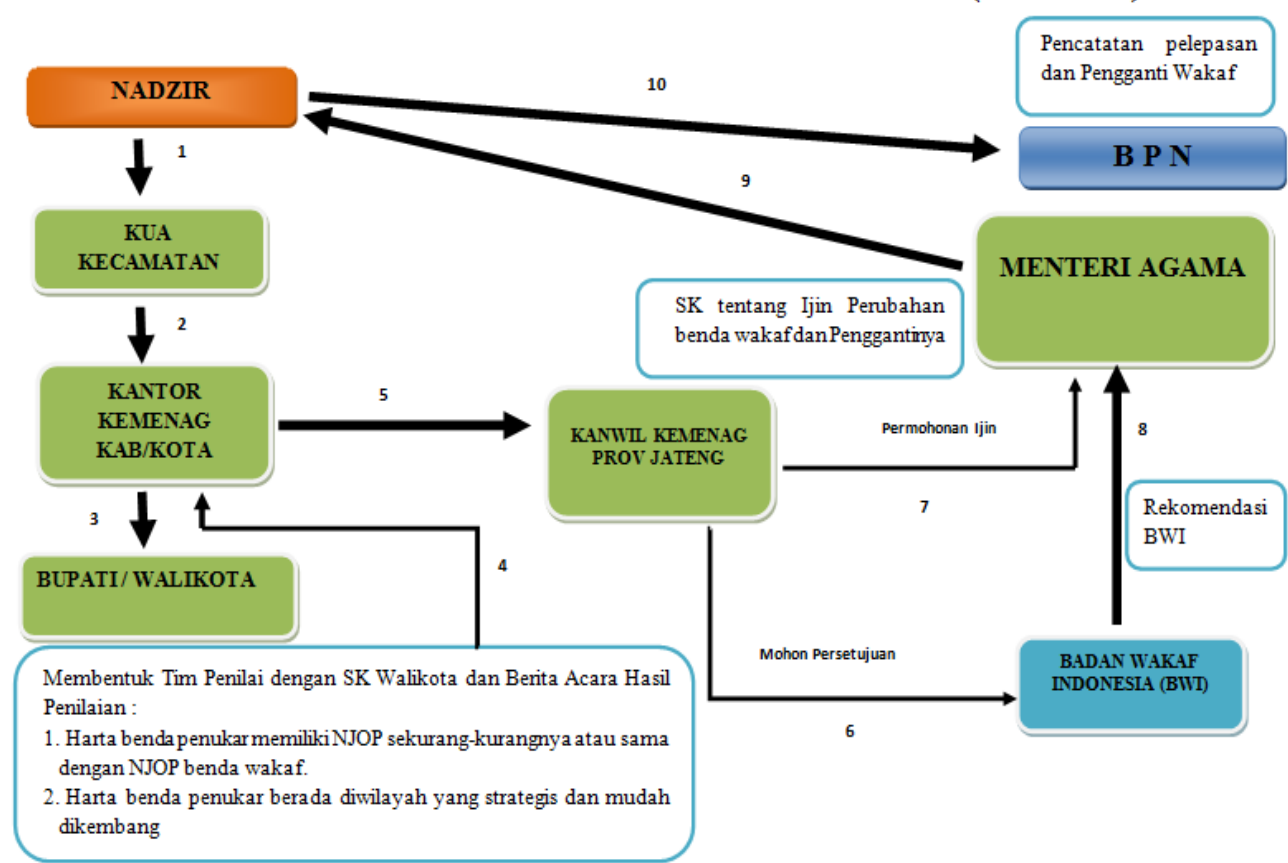

Namun dalam prakteknya mekanisme perubahan status harta benda wakaf yang terkena pengadaan tanah untuk pembangunan jalan tol Batang-Semarang II Seksi V di Kota Semarang belum sesuai sebagaimana diatur dalam Undang-undang. Di kecamatan Ngaliyan dn Kecamatan Semarang Barat Kota Semarang, sebagian besar telah dilakukan pembongkaran bangunan harta benda wakaf dan telah dilakukan pembangunan kembali di tanah pengganti wakaf meskipun belum ada Izin tertulis dari Menteri Agama dan Rekomendasi dari BWI.

2. Hal-hal yang menghambat proses perubahan status harta benda wakaf yang terkena pengadaan

tanah untuk pembangunan jalan tol Batang-Semarang II Seksi V di

\section{Kota Semarang}

Hal-hal yang dirasa menghambat proses perubahan status harta bend wakaf yang terkena pengadaan tanah untuk pembangunan jalan Tol BatangSemarang II Seksi V di Kota Semarang dapat digolongkan dalam 2 (dua) hal yakni karena faktor Internal dan faktor Eksternal sebagaimana diuraikan berikut:

\section{Faktor Internal}

\subsection{Nazhir}

Para Nazhir masih kurang memahami tentang tugas pokoknya 


\subsection{Kementerian Agama \\ Pihak Kementerian agama dalam melakukan pembinaan dan pengawasan pengelolaan harta benda wakaf khususnya kepada para Nazhir belum optimal, salah satu tolok ukurnya banyak nazhir yang harta bendanya terkena pembangunan jalan tol tidak memahami tentang perwakafan}

\subsection{Badan Wakaf Indonesia}

Bahwa dalam rangka memajukan dan menggembangkan perwakafan nasional secara sistematis, konsisten, dan efektif, Badan Wakaf Indonesia diberikan tugas dan kewenangan untuk memberikan persetujuan atas penukaran harta benda wakaf.

\subsection{Pemerintah Kota}

\section{Semarang}

Pihak Pemerintah Kota Semarang sebagai fasilitator dalam proses perubahan status harta benda wakaf belum berjalan optimal dalam mengkoordinanikan antar elemen lembaga yang terkait dalam penanganan perubahan status harta benda wakaf.

\section{Faktor Eksternal}

\subsection{Kesulitan mencari tanah pengganti.}

Selain karena dibatasi oleh rambu-rambu harga yang tidak boleh melampaui plafond nilai sebagaimana ditetapkan oleh Appraisal, juga terdapat kesulitan ketika diwilayah sekitar tidak tersedia lahan pengganti, sementara masyarakat memerlukan pengganti tempat ibadah yang tidak terlalu jauh dari lingkungannya.

\subsubsection{Kesesuaian Harga.}

Beberapa kasus dilapangan dijumpai, bahwa permintaan harga atas tanah pengganti oleh pemilik tanah masih terlalu tinggi sehingga melebihi harga yang telah ditentukan oleh Tim Penilai (Appraisal).

\subsubsection{Kesesuaian Tata Ruang (RTRW).}

Terdapat beberapa lokasi yang calon tanah pengganti sebagaimana diusulkan oleh Nazhir setelah dicek dan 
diploting dalam Peta Tata
Ruang, peruntukannya
merupakan lahan kawasan
konservasi atau lahan hijau.
Sehingga hal yang demikian
tidak sesuai dengan regulasi
yang ada mengenai Penataan
Ruang dan harus mencari
alternatif lainya.

\subsubsection{Kesesuaian Lingkungan}

\section{/ Lokasi.}

Terdapat beberapa usulan dari para Nazhir tentang tanah calon pengganti yang apabila dilihat dari harga dibawah Appraisal, Luas tanah lebih luas jika dibanding tanah wakaf semula, Namun letak /lokasi tanah dimaksud jauh dari pemukiman dan kurang strategis padahal rencana akan didirikan tempat ibadah berupa Masjid.

\subsection{Terdapat Penolakan dari} Warga Sekitar tanah pengganti.

Penolakan dari warga sekitar tanah pengganti ini terjadi pada kasus tanah calon pengganti makam yang terletak di Kelurahan Ngaliyan. Warga sekitar makam merasa keberatan dan melakukan

\begin{abstract}
penolakan atas rencana pembelian tanah yang akan digunakan sebagai tempat pemindahan makam yang terkena pembangunan jalan tol.
\end{abstract}

\subsection{Adanya Spekulan Tanah} / Kelompok Kepentingan.

Terdapat kelompok kepentingan tertentu dari unsur masyarakat yang mempengaruhi proses mekanisme perubahan status harta benda wakaf, karena kelompok ini akan mengambil keuntungan dengan adanya pembelian tanah pengganti harta benda wakaf yang akan dipilih.

\section{Penutup}

A. Kesimpulan:

a. Mekanisme perubahan status harta benda wakaf yang terkena pengadaan tanah untuk pembangunan jalan tol Batang-Semarang II seksi V di Kota Semarang saat ini dalam pelaksanaannya tidak berjalan sesuai ketentuan perundang - undangan sebagaimana diatur dalam 
Undang-undang Nomor 41

Tahun 2004 tentang wakaf dan Peraturan Pemerintah

Nomor 42 Tahun 2006

tentang pelaksanaan UU

No. 41 Tahun 2004.

Dengan semangat dalam

rangka percepatan

pembangunan infrastruktur

jalan tol sebagaimana diatur

dalam Peraturan Presiden

Nomor 58 tahun 2017

tentang perubahan atas

Peraturan Presiden Nomor 3

Tahun 2016 tentang

percepatan pelaksanaan

proyek stategis Nasional.

Sehingga pelaksanaan

perubahan status harta

benda wakaf yang terkena

pengadaan tanah untuk

pembangunan jalan tol

Batang-Semarang II Seksi V

di Kota Semarang

cenderung berbenturan

dengan ketentuan

perundang-undangan yang

mengatur tentang

mekanisme perubahan

status harta benda wakaf .

b. Hal-hal yang menghambat

proses perubahan status harta benda wakaf yang terkena pengadaan tanah untuk pembangunan jalan tol Batang-Semarang II Seksi V di Kota Semarang adalah :

2.1. Faktor Internal

2.1.1 Sebagian besar Nazhir masih kurang memahami tentang tugas Pokok dan Fungsi terkait perubahan status Harta Benda Wakaf yang terkena Jalan Tol.

2.1.2 Peran aktif dan koordinasi dari para pihak terkait antara lain : Nazhir, KUA, Kementerian

Agama (Pusat, Provinsi, Kota Semarang), BWI, dan Pemerintah Kota Semarang, PPK Jalan Tol, Badan Pertanahan Nasional dan Tim Pelaksana Pengadaan tanah 


$$
\begin{aligned}
& \text { dirasa belum } \\
& \text { maksimal dalam } \\
& \text { penyelesaian } \\
& \text { perubahan status } \\
& \text { Harta Benda Wakaf } \\
& \text { yang terkena Jalan } \\
& \text { Tol. }
\end{aligned}
$$

\subsection{Faktor Eksternal}

2.2.1 Kesulitan mencari tanah pengganti harta benda wakaf yang terkena Pembangunan Jalan Tol

2.2.2 Terdapat Penolakan dari Warga Sekitar tanah pengganti.

\subsubsection{Adanya Spekulan} Tanah / Kelompok Kepentingan

\section{B. $S$ a $r$ a n}

1. Diperlukan Peningkatan kapasitas kemampuan Sumber Daya Manusia para Nazhir dan pihak terkait lainnya agar pemahaman tentang tugas Pokok dan Fungsi Nazhir untuk kegiatan pengelolaan dan pengembangan harta benda wakaf menjadi lebih baik lagi dan berdaya guna.

2. Diperlukan koordinasi antar pihak yang terlibat dalam mekanisme perubahan ststus harta benda wakaf yang terkena pembangunan jalan tol antara lain : Para nazhir, KUA setempat, Kementerian Agama (Pusat, Provinsi, Kota ), BWI, Pemerintah Kota Semarang, PPK Jalan Tol, Badan Pertanahan Nasional, Tim Pelaksana Pengadaan tanah.

3. Diperlukan antisipasi sejak awal oleh Tim Perencanaan agar tanah pengganti Harta Benda Wakaf dimasukkan dalam penetapan lokasi agar pada saat pelaksanaan tidak mengalami kesulitan / hambatan.

4. Terkait proses percepatan dalam perolehan tanah pengganti, secara normatif disarankan agar ditempuh dengan model perikatan jual beli (PPJB) dan kuasa jual antara PPK Jalan Tol 


\begin{abstract}
(selaku Instansi yang
memerlukan tanah) dengan

para pemilik tanah yang

akan digunakan sebagai

tanah pengganti Harta

Benda Wakaf. Sehingga

proses yang dilakukan tidak

melanggar ketentuan

perundang-undangan yang

berlaku.
\end{abstract}

5. Diperlukan sosialisasi yang intensif dengan melibatkan sebanyak-banyaknya unsur masyarakat baik secara langsung maupun tidak langsung, agar masyarakat / pihak yang berhak memahami akan arti pentingnya pengadaan tanah untuk pembangunan kepentingan umum, khususnya terkait penggantian harta benda wakaf.

6. Diperlukan adanya Singkronisasi dan harmonisasi Peraturan perundang-undangan yang mengatur tentang wakaf dengan peraturan perundang - undangam tentang pengadaan tanah untuk pembangunan kepentingan umum dan regulasi tentang percepatan proyek strategis Nasional agar tidak bertabrakan dan memperlancar pelaksanaan kegiatan.

7. Diperlukan pemangkasan jalur birokrasi / penyederhanaan mekanisme, yakni perubahan status harta benda wakaf tidak harus menunggu izin dari Menteri Agama akan tetapi cukup didelegasikan kepada Kepala Kanwil Kementerian Agama Provinsi Jawa Tengah, sehingga lebih efektif dan efisien.

DAFTAR PUSTAKA

\section{A. Buku-Buku:}

Abdurrahman, 1991, Masalah Pencabutan Hak Hak Atas Tanah Dan Pembebasan Tanah Di Indonesia”, Bandung : PT Citra Aditya Bakti 
Abdurrahman, 1994,,Masalah
Perwakafan Tanah Milik
dan Kedudukan Tanah
Wakaf di Negara Kita,
Bandung, PT. Citra Aditya
Bakti

Adijani

Al-Alabij, 1992,Perwakafan Tanah di Indonesia dalam Teori dan Praktek, Bandung, Rajawali Press

Ahmad Azhar Basyir, 1987, Hukum Islam Tentang Wakaf Ijarah dan Syirkah, Bandung, Alma Arif

AP. Perlindungan, 1991,“Komentar Atas UUPA", Bandung : Mandar Maju

Arie S. Hutagalung, 2005, Tebaran Pemikiran Seputar Masalah Hukum Tanah, (Jakarta ; Lembaga Pemberdayaan HukumIndonesia,)

Boedi Harsono, 1999, Hukum Agraria Indonesia ( Sejarah Pembentukan Undang-
Undang Pokok Agraria), Djambatan, Jakarta

Boedi Harsono, 2004, “Masalah Kerangka Persoalan dan Pokok-pokok Kebijakan Pertanahan", dalam BF Sihombing, "Pergeseran Kebijakan Pengadaan Tanah Untuk Kepentingan Pemerintah dan Swasta" (Studi Kasus Pengaturan Pemilikan, Penguasaan Tanah di Provinsi DKI) Jakarta: UI

Brahmana Adhie dan Hasan Basri Nata Menggala, 1998, Reformasi Tanah, Mandar, Jakarta

Bungin, Burhan, 2001, Metodologi Penelitian Sosial: Formatformat Kualitatif dan Kuantitatif ,Surabaya, Airlangga Universitu Press.

Burhan Ashosofa, 2000, Metode Penelitian Hukum, (Jakarta: Rineka Cipta,) 
Direktrorat Jendral Bimbingan

Masyarakat Islam. 2011.

Tata Cara Perubahan

Status Tanah Wakaf.

Kementrian Agama RI

Djuhaendah Hasan, makalah

"Aspek ekonomi Dalam

Pengadaan Tanah Untuk

Kepentingan

Pembangunan", disampaika

$\mathrm{n}$ dalam Seminar Nasional

Pengadaan Tanah Untuk

Kepentingan Umum,

kerjasama Fakultas Hukum

UNPAD dengan Himpunan

Mahasiswa BKU Hukum

Bisnis, Jakarta, 14

September Tahun 2006.

Fiqih Sunnah buku ke-13, 1998, Bandung, PT. Alma Arif

Hardijan Rusli, 2006, Metode Penelitian Hukum Normatif, Bagaimana, (Law Review Fakultas Hukum Universitas Pelita Harapan, Volume V No. 3

Imam Taqiyuddin Abu Bakar ibn Muhammad al-Hussaini, Kifayahal-Akhyar Juz 1,
Beirut: Dar al-Kutub alIlmiah, tth

Maria S.W. Sumardjono, 2007, "Kebijakan Pertanahan": Antara Regulasi dan Implementasi, Jakarta : Buku Kompas

Michael G Kitay,1985, “Land Acquisition in Developing Countrie"s, Policies and procedures of public sector, with survey and case studies from Korea, India, Thailand, and Equador, Oelgeschlager. Gunn\&Hain, Boston : Publishers, Inc,

Mohammad Daud Ali, 1998, Sistem Ekonomi Islam Zakat dan Wakaf, Jakarta, Universitas Indonesia Press

Mukti Fajar dan Yulianto, 2010, Dualisme Penelitian Hukum Normatif dan Empiris, (Yogyakarta: Pustaka Pelajar) 
Oloan Sitorus, Dayat Limbong, 2004, "Pengadaan Tanah Untuk Kepentingan Umum,, Mitra Kebijakan Tanah Indonesia, Yokyakarta

Soimin, Soedharyo. 2008. Status Hak \& Pembebasan Tanah. Jakarta: Sinar Grafika

Sudarwan Denim, 2002, Menjadi Peneliti Kualitatif,

Rachmadi Usman, 2006, (Bandung: Pustaka Setia)

Perkembangan Pengelolaan Wakaf di Indonesia, Jakarta Direktorat Pemberdayaan Wakaf Direktorat Jenderal Bimbingan Masyarakat Islam

Sayyid Sabiq, Fiqh al-Sunnah, Beirut: Dar al-Fikr

Soedikno Mertokoesoemo.,1985, "Mengenal Hukum”, Yogyakarta : iberty

Soerjono Soekanto dan Sri Mamudji, 2009, Penelitian Hukum Normatif Suatu Tinjauan Singkat, Cetakan ke-11, (Jakarta, PT Raja Grafindo Persada,) (Jakarta:Rajawali)

Sumardjono, Maria S.W. 2009. Tanah Dalam Perspektif Hak Ekonomi, Sosial dan Budaya. Jakarta: PT. Kompas Media Nusantara

Syah, Mudakir Iskandar. 2015. Pembebasan Tanah Untuk Pembangunan Kepentingan Umum: Upaya Hukum Masyarakat Yang Terkena Pembebasan Dan Pencabutan. Jakarta: Soerjono Soekanto, 1985, Permata Aksara

Pengantar Penelitian

Hukum, (Jakarta: UI-Press) 
B. Undang-Undang:

- Undang-Undang Nomor 5

Tahun 1960 tentang Peraturan

Dasar Pokok-pokok Agraria ;

- Undang-undang Republik

Indonesia Nomor 41 Tahun

2004 tentang Wakaf ;

- Undang - Undang Nomor 2

Tahun 2012 tentang Pengadaan

Tanah Bagi Pembangunan

untuk Kepentingan Umum;

- Peraturan Pemerintah Republik

Indonesia Nomor 42 Tahun

2006 tentang Pelaksanakan

Undang-Undang Nomor 41

Tahun 2004 tentang Wakaf ;

- Peraturan Presiden Nomor 71

Tahun 2012 tentang

Penyelengaraan Pengadaan

Tanah Bagi Pembangunan

Untuk Kepentingan Umum

sebagaimana dirubah beberapa

kali dan terakhir dengan

Peraturan Presiden Nomor 148

tahun 2015 tentang perubahan

Keempat Peraturan Presiden

Nomor 71 Tahun 2012 tentang

Penyelengaraan Pengadaan

Tanah Bagi Pembangunan

Untuk Kepentingan Umum;

- Peraturan Presiden Nomor 3

Tahun 2016 tentang Percepatan
Pelaksanaan Proyek Strategis

Nasional;

- Peraturan Kepala Badan

Pertanahan Nasional Republik

Indonesia Nomor 5 Tahun 2012

tentang Petunjuk Teknis

Pelaksanaan Pengadaan Tanah

sebagaimana dirubah dengan

Peraturan Menteri Agraria dan

Tata Ruang / Kepala Badan

Pertanahan Nasional Nomor 6

Tahun 2015 tentang Perubahan

atas Peraturan Kepala Badan

Pertanahan Nasional Republik

Indonesia Nomor 5 Tahun 2012

tentang Petunjuk Teknis

Pelaksanaan Pengadaan Tanah.

- Peraturan Badan Wakaf

Indonesia Nomor 1 Tahun 2008

Tentang Prosedur Penyusunan

Rekomendasi Terhadap

Permohonan Penukaran /

Perubahan Status Harta Benda

Wakaf ;

C. Website

- Novianto M. Hantoro, http:

// berkas . dpr . go . id / pengkajian /files

/buku_tim/buku-tim-20.pdf

diakses pada tanggal 11

Pebruari 2018 pukul 20.00

WIB 
- SIWAK, Direktorat

Pemberdayaan Zakat dan

Wakaf Direktorat Jenderal

Bimbingan Masyarakat

Islam Kementerian Agama

Republik Indonesia Tahun

2018, diakses pada tanggal

25 Maret 2018 pukul 19.00

WIB 